\title{
On international cost-sharing of pharmaceutical $\mathrm{R} \& \mathrm{D}^{*}$
}

\author{
Pedro Pita Barros
Universidade Nova de Lisboa \\ Pedro Pita Barros
Universidade Nova de Lisboa \\ and CEPR (London)
}

\author{
March 2008
}

\begin{abstract}
Ramsey pricing has been proposed in the pharmaceutical industry as a principle to price discriminate among markets while allowing to recover the (fixed) R\&D cost. However, such analyses neglect the presence of insurance or the fund raising costs for most of drug reimbursement. By incorporating these new elements, we aim at providing some building blocks towards an economic theory incorporating Ramsey pricing and insurance coverage. We show how coinsurance affects the optimal prices to pay for the R\&D investment. We also show that under certain conditions, there is no strategic incentive by governments to set coinsurance rates in order to shift the financial burden of R\&D. This will have important implications to the application of Ramsey pricing principles to pharmaceutical products across countries.
\end{abstract}

Keywords: Ramsey pricing, coinsurance.

JEL numbers: I11, I18, L51

$\begin{array}{ll}\text { CORRESPONDENCE ADDRESSES: } \\ \text { Pedro Pita Barros } & \text { Xavier Martinez-Giralt } \\ \text { Faculdade de Economia } & \text { CODE and Departament d'Economia } \\ \text { Universidade Nova de Lisboa } & \text { Universitat Autònoma de Barcelona } \\ \text { Travessa Estêvão Pinto } & \text { Edifici B } \\ \text { P-1099-032 Lisboa } & \text { 08193 Bellaterra } \\ \text { Portugal } & \text { Spain } \\ \text { Fax: 351-21-3886073 } & \text { Fax: 34-93-581 24 61 } \\ \text { Email: ppbarros@fe.unl.pt } & \text { xavier.martinez.giralt@uab.cat }\end{array}$

\footnotetext{
${ }^{*}$ We thank comments and suggestions from A. Ma, A. McGuire, S. Felder and participants at the European conference on Health Economics held in Budapest, July 6-9, 2006. Financial support of Acção Integrada E97/04, and POCI/EGE/58934/2004 (Pedro P. Barros) and Financial support from the Barcelona Economics Program of CREA, and research projects HP2003-0066, 2005SGR00836, SEJ2006-00538-ECON and Consolider-Ingenio 2010 (Xavier Martinez-Giralt) is gratefully acknowledged. The usual disclaimer applies.
} 


\section{Introduction.}

This note addresses the interaction of pricing and insurance coverage in the pharmaceutical market. In particular, we assess the normative allocation of $R \& D$ costs across the different markets served by a pharmaceutical corporation under the presence of insurance. Our focus is on the implications of explicit recognition of health insurance coverage to the optimal Ramsey prices to finance pharmaceutical R\&D. We show that higher insurance coverage calls for higher prices not only because of lower demand elasticity but also due to a larger moral hazard effect in the consumption of pharmaceutical products.

$\mathrm{R} \& \mathrm{D}$ costs associated with new pharmaceutical products have increased substantially in the past three decades. DiMasi et al. (2003) estimate the total R\&D cost per new drug in 2001 at $\$ 802$ million. ${ }^{1}$ The Tufts Center for the Study of Drug Development (2003), increases the estimate further to $\$ 897$ million in $2003 .^{2}$

The sharp increase in $R \& D$ expenses combines, in the case of the pharmaceutical industry, with the traditional differences of drug prices across countries due to a number of factors. Among them, we find different regulatory regimes and insurance systems, together with governments that often are monopsonistic buyers of drugs. The foundations of these price differences are the object of intense debate as opposed to a policy of uniform prices supported by the presence of parallel imports or the use of the so-called reference pricing system. Danzon and Towse (2003) argue that these elements lie at the heart of the objective to set a single price within the European Union. Danzon (no date) argues against these practices as they are harmful to R\&D efforts. Her argument relies on two facts. On the one hand, $R \& D$ is a fixed cost once the new product is developed, and on the other hand, “(...) as R\&D costs cannot be rationally allocated as a direct cost of serving a specific country or consumer group, there is a strong incentive for each country to free-ride, leaving others to pay for the joint R\&D costs."

\footnotetext{
${ }^{1}$ See Frank (2003) for an assessment on how to interpret this estimation.

${ }^{2}$ One should read these estimates bearing in mind that allocating the R\&D cost of particular drug is not an easy task. Such costs span over a long period of time (see Toole, 2005), and also incorporate somehow the costs of failed attempts before succeeding with a new molecule.
} 
To support price differences across countries the use of Ramsey prices has been proposed. Ramsey (discriminatory) prices result from a welfare maximizing problem where firms obtain "normal" profit returns, allowing for the recovery of the fixed cost. The Ramsey rule determines prices above marginal cost. The amount by which price exceeds marginal cost is greater for goods with less elastic demand. This is known as the inverse elasticity rule.

This is a controversial issue. Raghavan (2001) contrasts the differential pricing for medicines as promoted by the WHO and the WTO, with the "exorbitant profits of the transnational pharmaceutical industry." Also, he argues that "to view essential drugs and medicines and their pricing in terms of high and low elastic demands of the consumer is not a preposition that can be sustained (...) in public health contexts." In the same vein Love (2001) claims that the "big problem with Ramsey pricing is that everyone loves to push the price discrimination part, which is pricing according to what people are willing to pay, but there is considerably less enthusiasm for the other part, which is the budget constraint. And, without the government regulation of the budget constraint, you just have monopoly pricing, which is not in fact efficient, in most cases, not to mention the ethical issues, or the rather messy empirical realities of industry pricing practices."

In contrast, Scherer (2001) assesses the evidence on the link between profits and R\&D effort in the US pharmaceutical industry. He concludes that “(...) as profit opportunities expand, firms compete to exploit them by increasing investments, primarily in $\mathrm{R} \& \mathrm{D}$, until the increases in costs dissipates most, if not all, supranormal profit returns." Also Danzon and Towse (2003) argue in favor of Ramsey prices as "(...) in the long run with unrestricted entry and exit of firms offering competing but differentiated products, dynamic competition will reduce expected profits to normal levels at the margin." Besides, Ramsey pricing assumes that the social value of an extra dollar of consumption of an individual is the same across markets. In western economies this may not be implausible, but when different markets are located in developed and developing countries, such an assumption is hard to maintain. 
To overcome this difficulty, Diamond (1975) proposed the so-called manyperson Ramsey rule as a generalization of the Ramsey pricing to allow for distributional concerns. Jack and Lanjouw (2003) apply this generalized rule to the cost-sharing of pharmaceutical innovation in an international context where world income distribution is used to adjust international pharmaceutical prices. They conclude that (i) with those adjustments, poor countries should not necessarily share any of the costs of $R \& D$, and (ii) the pricing structure is not related to that which would be chosen by a monopolist in a simple (proportional) way. The argument for sustaining price differentials is reinforced by the simulation study of Dumonliu (2001), where access to pharmaceuticals would be seriously impeded under a global uniform price.

We focus on the issue of how to impute the overall $R \& D$ costs in the pharmaceutical industry across countries in the presence of insurance regimes that may differ across countries. We depart from Danzon and Towse (2003) who propose to use the principle of Ramsey pricing to define the price differentials across markets to cover the (fixed) $\mathrm{R} \& \mathrm{D}$ costs. Their main concern is to have richer countries paying enough to allow for the recovery of R\&D costs associated with new drugs, while keeping prices low in developing countries, to ensure wide access to pharmaceuticals. Direct application of Ramsey pricing principles lead to this sort of differential pricing rules as long as consumers in low-income countries have a more price-elastic demand. Danzon and Towse (2003) comment on the role of insurance in making demand faced by pharmaceuticals to be more or less price sensitive. However, they do not investigate further the changes in the Ramsey pricing rule that result from differences between the price paid by consumers (net of insurance) and the value received by the firm.

Our approach attempts to make sense of the price differences across countries. To that end, we characterize the Ramsey prices maximizing aggregate welfare. The equilibrium pricing rule obtained differs from the standard Ramsey pricing rule in the sense that for equal demand elasticities, and given distortion cost of funds, a country with a higher coverage rate will have a higher price as well. This is 
due to the well-known ex-post moral hazard problem of health insurance. Since insurance implies a lower price at the moment of consumption, consumers tend to overspend, in the sense of marginal benefit being smaller than social marginal cost at the equilibrium. This effect is larger the higher the coverage rate, which motivates a higher price to partially correct it. Also, we examine some comparative statics effects. Among them, we find that governments do not have incentives to strategically use insurance copayment rates in the determination of prices.

To see intuitively why the level of insurance makes a difference, consider two markets (countries) with the same (constant) price elasticity of demand but different insurance levels. Assume that in one country insurance copayments are 50\% while in the other copayment is only $10 \%$. Efficient pricing à la Ramsey determines a higher price in the country where quantity is less distorted. This means that the country with the higher copayment should pay most of the R\&D costs, since little distortion in consumption seems to result. This brings to our context an effect that extends Besley (1988), who finds that the design of optimal (secondbest) insurance policies is driven by the trade-off between the economic losses from moral hazard and the gains from risk sharing.

This, some would say, just acknowledges that price elasticity of demand does still matter. However, this simple intuition fails to take into account an additional aspect. Different copayment rates yield different levels of the usual moral hazard problem of excessive consumption (as the price faced by consumers at the moment of consumption is zero). Therefore, a benevolent planner, as implied by the Ramsey optimal pricing problem, will actually want to take this into account.

The social planner may want to increase more the price in the market with higher copayment rate to counteract on the moral hazard effect. In addition, since there is some extra consumption under more insurance, the financing constraint is less binding than otherwise, allowing for lower prices.

The price setting problem will make a balance between the distortions needed to allow for recovery of the fixed cost and the compensation of the moral hazard effect. Together with the moral hazard problem generated by insurance, the way 
countries define copayments has to take into account the equity and access issues underlying the design of differential prices.

In terms of the discussion of high prices in rich countries/low prices in poor countries, as long as insurance coverage is more generous in richer countries, our point reinforces the efficiency argument for international pricing differentials. Our contribution in this literature is to provide some building blocks towards an economic theory incorporating Ramsey pricing and insurance coverage. Of course, what arrangement may actually be implemented influences the incentives of firms to perform R\&D.

The problem of sharing the R\&D fixed cost over several countries has a clear analogy with third-degree price discrimination. In this line, think of the welfare properties of third-degree price discrimination pioneered by Schmalensee (1981). He proved that under monopoly, necessary conditions for Ramsey prices to be welfare improving are that total sales increase over all markets. This result generated a stream of contributions addressing its generality. Galera and Zaratiegui (2006) show that under asymmetric oligopoly when third-degree price discrimination favors the lower cost firm, the welfare loss may be offset by the cost savings. Felder (2006) proposes to add to the distortion from the Ramsey prices another distortion originated from a subsidy to consumers as a way to offset the welfare reducing effect of price discrimination. Felder (2004) shows the advantages of a two-part tariff, using the standard result that price (of insurance coverage) will be equal to marginal cost, and the lump-sum payment divides surplus between the third-party payer and the firm. This lump-sum payment takes into account differences in the coinsurance rates across countries. Finally, Adachi $(2002,2005)$ also shows that Schmalensee's result does not hold either in the presence of consumer externalities.

However, our concern does not go into these considerations. We are interested in making sense of the differences in prices across countries instead. Our interest lies in understanding how different insurance coverage policies change the optimal Ramsey prices. We also address the question of whether such coverage policies will be used strategically by third-party payers in order to shift financial burden to 
others.

The paper is organized in the following way: next section presents the basic model. Section 3 discusses how Ramsey prices are distorted by the presence of coinsurance schemes (copayment and reference prices). Section 4 explores comparative statics and Section 5 provides further extensions. A section with conclusions closes the paper.

\section{The model}

We consider a set $I$ of countries where a pharmaceutical company sells a (patented) drug. We assume, for simplicity, that countries are identical in size and that individuals within each country are also identical and summarized by a representative consumer. Accordingly, there is no room for introducing equity concerns. On this issue the reader is referred to Jack and Lanjouw (2003). Countries differ in their health insurance arrangements covering pharmaceutical consumption.

Health care insurance reimbursement schemes are typically based either on a direct cost-sharing rule or on a reference price. Let $p_{i}$ be the price of the drug in country $i$. A coverage rate $s_{i} \in[0,1]$ in country $i$ means that the insurer bears a proportion $s_{i} p_{i}$ of the cost of the drug, ${ }^{3}$

An alternative insurance arrangement used in several countries is a reference price system. Reference price $\widehat{p}_{i}$ in country $i$ is defined as the price level above which the patient is fully responsible for the payment. For prices below the reference price, the insurer bears the cost of the drug provided.

In general, the price paid by the patient in country $i, p_{i}^{c}$, is given by

$$
p_{i}^{c}=p_{i}-\bar{p}_{i}\left(p_{i}\right), \quad \text { with } \quad \bar{p}_{i}\left(p_{i}\right)=(1-\delta) \hat{p}_{i}+\delta s_{i} p_{i}
$$

where $\bar{p}_{i}$ is the cost-sharing in case of need of medical care. For $\delta=1$ we obtain the coinsurance setting while for $\delta=0$ the reference pricing scheme arises. Values of $\delta \in(0,1)$ define mixed systems.

\footnotetext{
${ }^{3}$ We follow here the definition in Mossialos et al. (2007, p. 41) and the patient pays the remaining amount $\left(1-s_{i}\right) p_{i}$.
} 
Let $D_{i}\left(p_{i}^{c}\right)$ be the demand for the relevant drug in country $i \in I$. The pharmaceutical company has to recover R\&D costs, given by $F$, and has production costs given by a constant marginal cost $c$.

We assume the existence of a supra-national entity that will define prices as to maximize social welfare over a set $I$ of countries, ${ }^{4}$ under the constraint of recouping the $R \& D$ cost. All countries are valued equally. In a broader sense, discussion of international allocation of $R \& D$ costs of pharmaceutical products necessarily implies some sort of coordination mechanism across countries. We model the outcome of this coordination mechanism (which can be rounds of multilateral talks, for example) as being similar to that of a supra-national entity. ${ }^{5}$

From the point of view of the supra-national entity, the problem of determination of optimal prices, while recovering the cost of research and development expenditures, takes into account consumers' surplus, producers' surplus, and the payments made for drug reimbursement. This last element, introduces a public funds distortion cost in the case of a public insurer, or the insurance loading in the case of private insurance companies. We denote such distortion cost of funds by $\eta>0$. Thus, the social welfare function can be written as

$$
W=\sum_{i \in I}\left(\int_{p_{i}^{c}}^{\infty} D_{i}(p) d p-(1+\eta) \bar{p}_{i} D_{i}\left(p_{i}^{c}\right)+\left(p_{i}-c_{i}\right) D\left(p_{i}^{c}\right)\right)-F
$$

We discuss below the results obtained for the co-insurance regime. the same qualitative implications are obtained under reference pricing (see the appendix).

\section{Optimal Ramsey prices when insurance differs across countries.}

The consumer's price at the moment of consumption net of any insurance the consumer may have is given by

$$
p_{i}^{c}=p_{i}\left(1-s_{i}\right),
$$

\footnotetext{
${ }^{4}$ From a European perspective, this would correspond to the European Commission, Enterprise and Industry DG.

${ }^{5}$ The implications of distortions arising from this coordination mechanism are left for future research.
} 
where $s_{i}$ is the coverage rate and $p_{i}$ the price received by the pharmaceutical company, as described above $(\delta=1)$.

The problem of determination of optimal prices, while recovering the cost of research and development expenditures, is given by

$$
\begin{aligned}
\max _{\left\{p_{i}\right\}} W & =\sum_{i \in I}\left(\int_{p_{i}^{c}}^{\infty} D_{i}(p) d p-(1+\eta) s_{i} p_{i} D_{i}\left(p_{i}^{c}\right)+\left(p_{i}-c_{i}\right) D_{i}\left(p_{i}^{c}\right)\right)-F \\
\text { s.t. } & \sum_{i \in I}\left(p_{i}-c_{i}\right) D_{i}\left(p_{i}^{c}\right)-F=0 .
\end{aligned}
$$

The first-order conditions of this problem are:

$$
\begin{aligned}
\frac{\partial \mathcal{L}}{\partial p_{i}} & =-D_{i}\left(p_{i}^{c}\right)\left(1+s_{i} \eta\right)-s_{i}\left(1-s_{i}\right)(1+\eta) p_{i} \frac{\partial D_{i}}{\partial p_{i}^{c}}+ \\
& +(1+\lambda)\left[D_{i}\left(p_{i}^{c}\right)+\left(p_{i}-c_{i}\right)\left(1-s_{i}\right) \frac{\partial D_{i}}{\partial p_{i}^{c}}\right]=0, i \in I \\
\frac{\partial \mathcal{L}}{\partial \lambda} & =\sum_{i \in I}\left(p_{i}-c_{i}\right) D_{i}\left(p_{i}^{c}\right)-F=0
\end{aligned}
$$

Rearranging the first-order conditions, we can write, using (3)

$$
\frac{p_{i}-c_{i}}{p_{i}}=\frac{\lambda}{1+\lambda} \frac{1}{\varepsilon_{i}}+\frac{s_{i}}{1+\lambda} \kappa_{i}, \quad \kappa_{i} \equiv 1-\eta\left(\frac{1-\varepsilon_{i}}{\varepsilon_{i}}\right)
$$

where $\lambda$ is the Lagrange multiplier associated with the zero-profit constraint, and $\varepsilon_{i}=-\partial D / \partial p \times p / D$ denotes demand elasticity.

The distortion cost $\eta$ has an upper bound smaller than one. Most estimates put this value in a range around $0.2 .^{6}$ Also, the presence of insurance is likely to make demand inelastic with values in coverage contexts around 0.2 (Newhouse, 1993; Ringel et al, 2005). For those values, $\kappa_{i}$ takes positive values. Thus, heretofore, we will assume $1>\kappa_{i}>0$. Note that we cannot make a direct comparison with the equilibrium values under no insurance $\left(s_{i}=0\right)$, as $\lambda$ is an endogenous variable as well.

The equilibrium pricing rule obtained differs from the standard Ramsey pricing rule in the last term: for equal demand elasticities, Lagrange multiplier, and given

\footnotetext{
${ }^{6}$ For more details, see, inter alia, Allgood and Snow (2006) and Fullerton (1991).
} 
distortion cost of funds, a country with a higher coverage rate will have a higher price as well. This is due to the well-known ex-post moral hazard problem of health insurance. Since insurance implies a lower price at the moment of consumption, consumers tend to overspend, in the sense of marginal benefit being smaller than social marginal cost at the equilibrium. This effect is larger the higher the coverage rate, which motivates a higher $p_{i}$ as to partially correct it.

This additional motive for price differentials may, or may not, reinforce price dispersion across countries. Whenever besides lower price elasticity of demand, richer countries also have a higher insurance coverage, then they should face higher prices than low-income countries for efficiency reasons alone.

This result also implies that assessment of international price dispersion cannot be made on the basis of marginal cost and price elasticity of demand differences. One must also look at coverage rate variations.

It is also noteworthy that Ramsey pricing is still not supportive of a policy of uniform prices across countries. It may accidentally occur that $\varepsilon_{i}$ and $s_{i}$ are such that price-cost margins are equal across countries, but a small perturbation in the fixed cost $F$ would destroy such uniform prices. In other words, from (7) and given $\left(c_{i}, c_{j}\right)$, there may exist $\left(s_{i}, s_{j} ; \varepsilon_{i}, \varepsilon_{j}\right)$ such that $\left(p_{i}-c_{i}\right) / p_{i}=\left(p_{j}-c_{j}\right) / p_{j}$.

The existence of insurance has actually another indirect effect. Holding prices constant, increasing the coverage rate means more revenues to the company as consumption expands. This helps to finance the fixed costs. Therefore, $\lambda$ also varies, in equilibrium, with exogenous shifts in the coverage rate.

The comparison of prices for distinct levels of the coverage rate cannot be fully assessed from the mere statement of first-order conditions. A full comparative statics exercise must be performed, which we report below for the two-country case.

\section{Comparative statics in a two-country market}

We are now interested in understanding how different coverage rates translate into price differences in an agreement to share $R \& D$ costs according to the Ramsey 
principles. To this purpose, the analysis below discusses how do optimal prices change when a country (say, country 1 ) increases its coverage level (decreases the co-insurance rate faced by consumers).

A full assessment of this question calls for a model where prices are set centrally and countries can determine their insurance coverage rates either in a simultaneous or sequential way. Such model would go beyond the scope of this note. Instead we propose to look at the local effects around the equilibrium prices.

Assume, for ease of computation, but without loss of generality) that we have two countries, $I=\{1,2\}$. Total differentiation of first-order conditions yields, for a change in $s_{1}$,

$$
\begin{aligned}
\frac{\partial^{2} \mathcal{L}}{\partial p_{1}^{2}} d p_{1}+\frac{\partial^{2} \mathcal{L}}{\partial p_{1} \partial \lambda} d \lambda+\frac{\partial^{2} \mathcal{L}}{\partial p_{1} \partial s_{1}} d s_{1}=0 \\
\frac{\partial^{2} \mathcal{L}}{\partial p_{2}^{2}} d p_{2}+\frac{\partial^{2} \mathcal{L}}{\partial p_{2} \partial \lambda} d \lambda=0 \\
\frac{\partial^{2} \mathcal{L}}{\partial \lambda \partial p_{1}} d p_{1}+\frac{\partial^{2} \mathcal{L}}{\partial \lambda \partial p_{2}} d p_{2}=0
\end{aligned}
$$

where $\mathcal{L}$ denotes the Lagrangian function of the optimization problem.

We solve this system for $d p_{i} / d s_{1}$ and $d \lambda / d s_{1}$. The comparative statics exercise establishes: $^{7}$

$$
\frac{d p_{1}}{d s_{1}} \lessgtr 0, \quad \frac{d p_{2}}{d s_{1}}<0, \quad \frac{d \lambda}{d s_{1}}<0 .
$$

These results imply the following. An increase in the coverage rate in country 1 increases overall consumption and allows to finance more easily the R\&D costs (the amount $F$ ). This alleviates the constraint faced $\left(d \lambda / d s_{1}<0\right)$, which in itself would allow for a reduction of prices in both countries. In country 2 there are no further effects and an increase in the coverage rate in country 1 should decrease the optimal Ramsey price in country $2\left(d p_{2} / d s_{1}<0\right)$. On country 1 , however, an increase in the coverage rate also increases the moral hazard issue (the subsidy must also be paid, and at the margin consumption occurs where marginal benefit is already below marginal costs). To control for this, the price in country 1 should

\footnotetext{
${ }^{7}$ On top of the usual regularity conditions stated previously, we also make use of the assumption of a concave or not too convex demand function to ensure $\partial^{2} \mathcal{L} / \partial p_{1} \partial s_{1}>0$.
} 
increase. Thus, the effect of raising coverage in a country can be a decrease or an increase of its price in the optimal Ramsey pricing system.

However, we are able to obtain some clear cut comparative statics results regarding the impact on the relative contributions of the countries to the financing the fixed cost when country 1 increases its coverage rate. Thus, assume country 1 increases $s_{i}$ and compute the impact on country 2's contribution in financing the $R \& D$ cost. This is given by,

$$
\begin{gathered}
\frac{\partial p_{2}}{\partial s_{1}}\left(D_{2}+\left(p_{2}-c_{2}\right)\left(1-s_{2}\right) \frac{\partial D_{2}}{\partial p_{2}}\right)=\frac{\partial p_{2}}{\partial s_{1}} D_{2}\left(1-\varepsilon_{2} \frac{\left(p_{2}-c_{2}\right)}{p_{2}}\right)= \\
\frac{\partial p_{2}}{\partial s_{1}} D_{2} \frac{1-\varepsilon_{2}-s_{2}-\kappa_{2}}{1+\lambda}<0
\end{gathered}
$$

where we have made use of (7) and (11).

Therefore, in our two-country world, if a country increases its coverage level $s_{i}$, it will induce a decrease in country j's contribution to the fixed R\&D cost. Accordingly, as the full R\&D outlays have to be funded, necessarily in our two-country world, country $i$ must increase its contribution.

Optimal prices do depend on coverage policies (reimbursement level) adopted by each and very country. As one can see from comparative statics results, we cannot infer that a higher level of coverage necessarily leads to a higher (or lower) price in that country. And, as discussed above, a higher coverage policy means that a country bears a higher burden in financing R\&D investment. From this observation, one might be tempted to conjecture that countries may try to play against the Ramsey price system, decreasing coverage to reduce their share of the burden. Such conjecture is, however, incorrect.

\section{Further extensions}

\subsection{Country-specific coverage decisions}

Another implication of the analysis is related to the interaction between coverage decisions at the country level and prices determined, on international agreement, according to the Ramsey principles outlined. Coverage decisions at the country level are determined by the value of pharmaceutical consumption (as specified for 
each country $i$ in the social welfare measure defined in (2)) and by the valuation attached to insurance coverage provided to people. As long as the later are countryspecific (that is, there are no cross-country externalities), then no country has an incentive to strategically use the coverage policies to influence the price outcome. Determination of how the R\&D cost is divided across countries according to a set of prices (given coverage policies) and each country's decision on the level of insurance coverage for pharmaceutical products are independent problems. This is a consequence of prices resulting from the solution to an optimization problem. ${ }^{8}$

\subsection{Welfare}

It is relevant to note that in our setup the coverage rate $s_{1}$ is overall welfare decreasing $\left(d \mathcal{L} / d s_{1}<0\right)$, as

$$
\frac{\partial \mathcal{L}}{\partial s_{1}}=p_{1}^{2} \frac{\partial D_{1}}{\partial p_{1}^{c}} \frac{\lambda}{\varepsilon_{1}}<0
$$

where we have made use of (7).

This is not surprising as the coverage rate plays only the role of a price subsidy here. This is so because we have not modeled the costs of bearing risk, and the welfare gains of insurance, which would work in the opposite direction in what respects the total effect.

With explicit consideration of the insurance arrangements, price equal to marginal cost is not optimal even for $\lambda=0$. That is, even if revenues under normal market conditions are sufficient to cover the $R \& D$ costs, it is optimal to have price above marginal cost.

\subsection{Arbitrage across countries}

We finally discuss the role of arbitrage across countries. The existence of arbitrage means one additional constraint in the choice problem of the Government, which

\footnotetext{
${ }^{8}$ It results from a straightforward application of two-stage games solving techniques- The game we consider has first countries choosing the level of coverage and, in a second stage, the prices are determined according the Ramsey principles to share the R\&D burden. The key elements for the result are the country-specific valuations of insurance coverage as the cross-effects of coverage on prices are of second-order, by application of the envelope theorem.
} 
does not improve with respect to its absence. An immediate implication of perfect arbitrage between countries is that prices will be equal in both countries, which in turn makes the price to the consumer to be fully determined by the financial constraint.

\subsection{The moral hazard case for cost-sharing}

Another issue that can be addressed in our framework is the desirability of having a cost-sharing driven by the need to finance the $R \& D$ costs, against the alternative of consumers paying the full price.

Lets us consider the general price defined in (1)and the associated welfare function is given by (2). The impact of an exogenous change in the cost-sharing is

$$
\frac{d W}{d \bar{p}_{i}}=(1+\eta) \bar{p}_{i} \frac{\partial D_{i}}{\partial p_{i}^{c}}+\left(p_{i}-c_{i}\right) \frac{\partial D_{i}}{\partial p_{i}^{c}}\left(\frac{\partial p_{i}}{\partial \bar{p}_{i}}-1\right)+\left(p_{j}-c_{j}\right) \frac{\partial D_{j}}{\partial p_{j}^{c}} \frac{\partial p_{j}}{\partial \bar{p}_{i}}, j \neq i
$$

Evaluated at $\bar{p}_{i}=0$, and given that from the comparative statics results, $\partial p_{i} / \partial \bar{p}_{i}<$ $1, \partial p_{j} / \partial \bar{p}_{i}<0$, one obtains $d W / \bar{p}_{i}>0$. Therefore, for positive $\mathrm{R} \& \mathrm{D}$ costs to be financed, under the assumption of unitary social cost of funds, it is welfare improving to have a positive cost-sharing.

We find this result remarkable because, even without considering the welfare effects of insurance, it turns out that a positive contribution by consumers at the point of consumption to finance a fixed $R \& D$ cost is welfare enhancing.

\section{Final remarks}

We have addressed here the problem of sharing pharmaceutical R\&D costs across countries. The standard Ramsey pricing model has to be adjusted for the existence of insurance coverage policies. Although previous works recognized the role of the insurance effects (Danzon and Towse, 2003, Felder, 2004, 2006), they did not explore fully its implications.

From our model, for equal demand structure, a higher coverage leads to a higher price in the optimal Ramsey pricing system. Moreover, in general, we cannot relate price dispersion across countries to differences in price elasticity of 
demand. This holds true both in a co-insurance regime and in a reference pricing system for pharmaceutical cost-sharing policy by the third-party payer.

The impact of an increase in coverage in one country has an ambiguous effect upon the optimal price in that country: the impact on the moral hazard effect calls for a price increase; on the other hand, it also increases consumption, making it easier to finance the R\&D fixed cost and allowing for lower prices.

Our analysis is relevant for two different discussions taking place at international fora. The first one is how to share the cost of bringing new drugs to the market between developed and developing countries (Danzon and Towse, 2003). To the standard arguments, we add that countries with a higher level of health insurance protection, be it from private or public origin, should bear higher prices. As developed countries have, in general, more extensive and sophisticated health insurance mechanisms, we should see in them higher prices, based in economic efficiency arguments.

The second discussion is related to the work at the European Commission level on pricing and reimbursement for new pharmaceutical products. Previous discussions have hinted at a common ex-factory price over Europe, which is not supported by our model (nor by the simple Ramsey rule). The current public face of such concerns is the Pharmaceutical Forum set by the European Commission in June 2005, and its Working Group on Pricing. ${ }^{9}$

We show that differences in health insurance coverage levels do matter for the discussion. This may add, or compensate for, the usual implication of Ramsey pricing of charging higher prices to low demand price elasticity groups (as distortions in quantities consumed by those groups are smaller).

One may fear that any international agreement, either at the European Union level or broader, may be prone to strategic behavior, namely through manipulation of insurance coverage levels as they influence the "optimal prices" for each country. However, due to the moral hazard aspect of health insurance, our model suggests this risk is minimal.

\footnotetext{
${ }^{9}$ The Pharmaceutical Forum is considered by the European Commission as a "high level political platform" to discuss "competitiveness and related public health issues".
} 
The determination of the optimal coverage policy has not been addressed here in an explicit way. We can, nonetheless, establish that such problem does not introduce strategic behavior by Governments as long as country-specific valuations of insurance coverage prevail. Returning to the argument of Danzon (no date), our analysis suggests that although efforts to shift burden to other countries may exist, coinsurance policies will not be used for such purpose (whenever benefits are country specific). Therefore, discussion of the price system that distributes the $R \& D$ cost across markets can be done independently of how the coinsurance levels are determined in each country. 


\section{References}

Adachi, T., 2002, A note on third-degree price discrimination with interdependent demands, Journal of Industrial Economics, 50: 235.

Adachi, T., 2005, Third-degree price discrimination, consumption externalities and social welfare, Economica, 72: 171-178.

Allgood, S. and A. Snow, 2006, Marginal welfare costs of taxation with human and physical capital, Economic Inquiry, 44: 451-464.

Besley, T., 1988, Optimal reimbursement health insurance and the theory of Ramsey taxation, Journal of Health Economics, 7: 321-336.

Danzon, P.M., (no date), Parallel trade and comparative pricing of medicines: poor choice for patients?, www.pfizerforum.com

Danzon, P.M., and A. Towse, 2003, Differential pricing for pharmaceuticals: reconciling access, R\&D and patents, International Journal of Health Care Finance and Economics, 3: 183-205.

Diamond, P., 1975, A many-person Ramsey tax rule, Journal of Public Economics, 4: 335-342.

DiMasi, J.A., R.W. Hansen, and H.G. Grabowski, 2003, The price of innovation: new estimates of drug development costs, Journal of Health Economics, 22: 151-185.

Dumonliu, J., 2001, Global pricing strategies for innovative essential drugs, International Journal of Biotechnology, 3(3/4): 338- 349.

Felder, S., 2004, Drug price regulation under consumer moral hazard: Two-part tariffs, uniform price, or third-degree price discrimination, European Journal of Health Economics, 49: 324-329.

Felder, S., 2006, Third-degree price discrimination in the presence of subsidies, German Economic Review, forthcoming.

Frank, R.G., 2003, Editorial. New estimates of drug development costs, Journal of Health Economics, 22: 325-330.

Fullerton, D., 1991, Reconciling recent estimates of the marginal welfare cost of taxation, American Economic Review, 81: 302-308.

Galera, F., and J.M. Zaratiegui, 2006, Welfare and output in third-degree price discrimination: A note, International Journal of Industrial Organization, 24: 605-611.

Jack, W., and J.O. Lanjouw, 2003, Financing pharmaceutical innovation: how much should poor countries contribute?, Center for Global Development, working paper No. 28.

Love, J., 2001, Policies that ensure access to medicine and promote innovation, with special attention to issues concerning the impact of parallel trade on the competitive sector, and a trade framework to support global R\&D on new health inventions, WHO/WTO Joint Secretariat Workshop on Differential 
Pricing and Financing of Essential Drugs, Hoshjor, Norway. Available at http://www.cptech.org/ip/health/econ/jamie-hosbjor.html

Mossialos, E., S. Allin and J. Figueras (eds.), 2007, Health systems in transition: Template for analysis, Copenhagen, WHO Regional Office for Europe on behalf of European Observatory on Health Systems and Policies.

Newhouse, J., 1993, Free for all? Lessons from the RAND Health Insurance Experiment, Cambridge (Mass.), Harvard University Press.

Raghavan, C., 2001, Differential pricing for drugs to help people or corporations, http://www.twnsite.org.sg/title/pricing.htm.

Ringel, J., S. Hosek, B. Vollaard, and S. Mahnovsky, 2005, The elasticity of demand for health care - A review of the literature and its application to the Military Health System, Rand Health report, consulted at http://www.rand.org/pubs/monograph_reports/2005/MR1355.pdf.

Scherer, F.M., 2001, The link between gross profitability and the pharmaceutical R\&D spending, Health Affairs, 20(5): 216-220.

Schmalensee, R., 1981, Output and welfare implications of monopolistic thirddegree price discrimination, American Economic Review, 71: 242-247.

Toole, A., 2005, The evolving US pharmaceutical research enterprise, Economic Realities in Health Care Policy, 4(1): 3-9.

Tufts CSDD, 2003, Post-approval R\&D raises total drug development costs to $\$ 897$ million, Impact Report, 5(3), May/June.

\section{Appendix: Reference prices}

A reference price $\widehat{p}_{i}$ as defined above means that $p_{i}^{c}=p_{i}-\widehat{p}_{i}$. The welfare measure of the supra-national authority is given by the lagrangian function of the welfare maximization problem, that is,

$$
\begin{aligned}
\max _{\left\{p_{i}\right\}} W & =\sum_{i \in I}\left(\int_{p_{i}^{c}}^{\infty} D_{i}(p) d p-(1+\eta) \widehat{p}_{i} D_{i}\left(p_{i}^{c}\right)+\left(p_{i}-c_{i}\right) D_{i}\left(p_{i}^{c}\right)\right)-F \\
\text { s.t. } & \sum_{i \in I}\left(p_{i}-c_{i}\right) D_{i}\left(p_{i}^{c}\right)-F=0
\end{aligned}
$$


The corresponding first-order conditions for welfare maximization are

$$
\begin{aligned}
\frac{\partial \mathcal{L}}{\partial p_{i}} & =-D_{i}\left(p_{i}^{c}\right)-(1+\eta) \hat{p}_{i} \frac{\partial D_{i}}{\partial p_{i}^{c}}+ \\
& +(1+\lambda)\left[D_{i}\left(p_{i}^{c}\right)+\left(p_{i}-c_{i}\right) \frac{\partial D_{i}}{\partial p_{i}^{c}}\right]=0, i \in I \\
\frac{\partial \mathcal{L}}{\partial \lambda} & =\sum_{i \in I}\left(p_{i}-c_{i}\right) D_{i}\left(p_{i}^{c}\right)-F=0
\end{aligned}
$$

From these expressions, we can easily obtain the comparative statics of an increase in $\hat{p}_{1}$ in a two-country world. Similar to what happens with the coverage arrangement,

$$
\frac{d p_{1}}{d \widehat{p}_{1}} \lessgtr 0 ; \quad \frac{d p_{2}}{d \widehat{p}_{1}}<0 ; \quad \frac{d \lambda}{d \widehat{p}_{1}}<0
$$

Therefore, the qualitative effects are the same as under the coverage arrangement. 